\title{
Facing the complexity of the economy: an opportunity for the new alliance between economics and engineering
}

\section{Silvano Cincotti $^{1}$}

Received: 16 September 2021 / Accepted: 21 September 2021 / Published online: 8 October 2021

(c) The Author(s) 2021

\begin{abstract}
In Forging a new alliance between economics and engineering, Sergio Mariotti explores the relationship between economics and engineering. The interactions between economics and engineering is a question rather than trivial and Mariotti faces the problem, firstly, from an historical perspective and, secondly, by identifying the paradigms for the economics-engineering nexus. Three paradigms are proposed, i.e., economics for engineering, economics and engineering, economics as engineering. They offer the opportunity to open new vistas on the future of the relationships between economics and engineering, in particular for facing the complexity of the economy.
\end{abstract}

Keywords Expectations $\cdot$ Rationality $\cdot$ Complexity $\cdot$ Agent-based macroeconomics

JEL Classification D4 D D8 E E1 E E7

\section{Introduction}

Sergio Mariotti (2021) explores the relationship between economics and engineering. The strategy is, first, to start from the historical perspective on the relationships between economics and engineering and, second, to identify the paradigms for the economics-engineering nexus.

The relationships between economics and engineering is a question rather than trivial. The literature offers a long history of contributions, from Hayford (1917) to Morgan (2012) and more recently Duarte and Giraud (2020) and Blockley (2020). Mariotti provides a review of the different contributions and, in addition to being enjoyable and informative, Forging a new alliance between economics and engineering offers a reconstruction of the dynamics of such interaction and of its

Silvano Cincotti

silvano.cincotti@unige.it

1 DIME-DOGE, University of Genoa, via Opera Pia 15, 16145 Genova, Italy 
complexity. Three paradigms are proposed: (i) economics for engineering; (ii) economics and engineering; (iii) economics as engineering.

The "economics for engineering" paradigm has a long tradition and Mariotti helps us in understanding the motivations behind such paradigm and in reconstructing the successful experiments started in the US in the second half of the XIX century and then spread worldwide in global and shared experiences.

The latter paradigm (i.e., "economics as engineering") underlines the positivism of a scientific approach to economics based on the (hidden) assumption that economics is different and must be distinguished from the social sciences. Mariotti remarks that this is just one of the several metaphors than can be used to sketch the needs of solutions that permit "engineering" applications in economics and (more often) in finance. Several Nobel Prizes winners can be described as "economic engineers": Harry Markowitz, Merton Miller, and William Sharpe won in 1990 for "pioneering work in financial economics", Robert Merton and Myron Scholes in 1997 "for a new method to determine the value of derivatives", Lloyd Shapley and Alvin Roth in 2012 "for the theory of stable allocations and the practice of market design" and Paul Milgrom and Robert Wilson, in 2020, for "improvements to auction theory and inventions of new auction formats." It is worth remarking that beside these examples that have reached the degree of durable consensus as economic engineering, one can recognize the economics as engineering paradigm also in the need of theoretical models aiming at solving the central problem of policy making, but in fact leading to an excess of confidence in classical theoretical models. This open relevant questions and will be addressed in the following Sections.

Finally, the paradigm "economics and engineering", that Mariotti represents as "a meeting between peers, respecting the disciplinary singularities and the different cultures, but in a context of cross-fertilization and sometimes of interdisciplinarity" (Mariotti, 2021, Sect. 2). «How dare you?» might wonder some orthodox economists, but in fact cross-fertilization and interdisciplinarity are ordinary in science. Moreover, in Forging a new alliance between economics and engineering Mariotti prompts out that cross-fertilization, interdisciplinarity and multidisciplinarity have been going always in the relationship between economics and engineering. Furthermore, they are strengthening as a consequence of the growth of the complexity approach to science and this will be addressed in the following Sections.

\section{Expectations in economics}

The Phillips curve is a central empirical result in economics that identifies a tradeoff between the rate of unemployment and the rate of inflation. It was found by Phillips (1958) and its centrality role in economics arises from the fact that the dynamics of inflation is a function of the state of the real economy and of the inflation expectations.

The Phillips curve is the first empirical evidence of the role of expectations in economics. It has induced lots of theoretical work and led to lots of Nobel prizes (Friedman, Klein, Tobin, Modigliani, Haavelmo, Mundell, Phelps, etc.). Among them, the Phillips curve was the basis of Lucas's (1976) critique that resulted in a 
turning point in economic theory. Indeed, in the 50's the state of the art on macroeconomics was rooted on the masterpiece by Keynes (1936). The Keynesians framework overcomes the limit of the demand-supply approach and shows how the fiscal policy might be countercyclical, thus leading to the famous multipliers. In particular, Keynesians assume that their multipliers are useful because they are fixed numbers, but within the mechanism of economic expectations originated by the Phillips curve, the Keynesian partial derivatives were not structural, i.e., the multipliers depend on the policy. Thus, a policy that is chosen based on a multiplier can change that multiplier leading to an effect that cannot be envisioned from the Keynesian model.

The Phillips curve resulted in an earthquake in economics and the area of debate was on the theoretical explanation of the Phillips curve (particularly during the 60's and 70's) centered on the following question: how do heterogeneous economic agents determine the expected inflation?

It is worth remarking that this is a fundamental question, with many intriguing and complex scientific implications, but still lacking of an answer. It can be reasonably assumed that as an exit strategy, such fundamental question was reframed into a more convenient problem: should one focus on trying to explain correctly the mechanism that generates these expectations, or should one just try to find a "method" that produces the correct answer?

The answer to the demand of such a "method" is the rational expectations mechanism: a rational agent does not make systematic errors and due to his ability, knowledge and tools, there can only exists representative agents. The rational expectations approach, however, does not give indication about the way expectations are reached: in reality, how do badly-informed bounded-rational agents manage to "guess" the right solution? Within the rational expectations one assumes that a mechanism exists, but it is not revealed (dogma of faith).

Based on rational expectations, modern neoclassical macro-economists have built more and more abstract and mathematically sophisticated models aiming at solving the central problem of policy-making, but in fact leading to an excess of confidence in their model. The "central problem of depression-prevention has been solved," stated Robert Lucas in the 2003 presidential address to the American Economic Association. In 2004, Ben Bernanke (lately President of the Federal Reserve) celebrated the «Great Moderation» in economic performance over the previous two decades, which he attributed in part to improved economic policy making. Then, the financial crisis arose in 2007-2008 and speaking of the "efficient markets hypothesis" at the House of Representatives Committee on Government Oversight and Reform in October 2008, Alan Greenspan's testimony was "The whole intellectual edifice collapsed in the summer of last year."

Indeed, during the crisis 2007-2008, the world's financial system experienced a virtual collapse that had dire consequences for the real economy. The explanations given involve networks of banks, trust and contagion at all levels. These are not features of, nor characteristic of, classical economic models. They are typical of complex systems.

According to Greenspan, the financial crisis in 2007-2008 could have caused the collapse of modern economic theory in analogy to what happened to the Keynesian 
framework with the Phillips curve and heterodox economists are still waiting for that. More prudently, Jean-Claude Trichet, former President of the ECB, in his speech at the opening address at the Trichet (2018) remarked the needs to enrich modern economic theory and prompted out that "First, we have to think about how to characterise the homo economicus at the heart of any model... We need to deal better with heterogeneity across agents and the interaction among those heterogeneous agents. ...Second, we may need to consider a richer characterisation of expectation formation. Rational expectations theory has brought macroeconomic analysis a long way over the past four decades. But there is a clear need to re-examine this assumption. ... Third, we need to better integrate the crucial role played by the financial system into our macroeconomic models."

Curiously, in his speech Trichet suggested a viable way to reach those goals and stated "In this context, I would very much welcome inspiration from other disciplines: physics, engineering, psychology, biology. Bringing experts from these fields together with economists and central bankers is potentially very creative and valuable..." Unfortunately, for the European Union it was just a speech and the ECB monetary policy during his mandate remained rooted on the modern neoclassical economic doctrines of inflation control and austerity. Conversely, Ben Bernanke when became President of the Federal Reserve quickly forgot his neoclassical economic root as a scholar and moved promptly to the status of pragmatic economist by introducing a huge quantitative easing as response to the financial crisis in 2007-2008, whereas Europe had to wait Mario Draghi to see the ECB monetary policy changing toward "unconventional" measures.

Even if just by chance and irrespective to his policy making during his mandate, Trichet speech supports the need of a new alliance between economics and engineering, in line with the paradigm of "economics and engineering", a meeting between peers, respecting the disciplinary singularities and the different cultures, but in a context of cross-fertilization, interdisciplinarity and sometimes transdisciplinarity as proposed by Sergio Mariotti.

\section{Economics and information technologies}

Information technologies have largely impacted the XX century. During the 60's, advances in computing led to machine programming, which opened the door to progressive automation and to the Third Industrial Revolution. Schwab (2016) coined the concept of the Fourth Industrial Revolution with the following definition: "The Fourth Industrial Revolution creates a world in which virtual and physical systems of manufacturing cooperate with each other in a flexible way at the global level". The Fourth Industrial Revolution is having economic, technological and social transformations at the global level and open direct demands of cooperation between economics and engineering for economic innovation, economic development, innovation management, etc.

The information technologies developments are examples of tremendous innovation processes. Schumpeter (1943) popularized the term "creative destruction" in economics. In Schumpeter's theory, Walrasian equilibrium is not adequate to 
capture the key mechanisms of economic development and Christopher Freeman (2009) states that "the central point of his [Schumpeter's] whole life work [is]: that capitalism can only be understood as an evolutionary process of continuous innovation and 'creative destruction' [This] is still not taken into the bosom of mainstream theory, although many now pay lip service to it.", thus reinforcing the needs to overcome the limits of modern economic theory.

Information technologies have also changed financial systems in unpredicted ways. During the 60's stock exchanges started considering the switching from faceto-face human trading to fully automated trading platforms. Regardless of whether markets were human or automated, the opportunities offered by information technologies were expected to improve market efficiency due to low costs, continuous trading, fairness and random price movements, see Black (1971). The stock markets have largely introduced innovations related to information technologies and these led to more and more computationally efficient high frequency automated trading platforms. This opened an opportunity for high frequency algorithm trading and dedicated software have been developed and used in the financial sector. On May 6th, 2010 the Commodity Futures Trading Commission and the Securities and Exchange Commission of the United States jointly reported the first case of what is currently known as Flash Crash (CFTCS-SEC, 2010). In the course of about 36 min starting at 2:32 pm ET-US, financial markets experienced one of the most turbulent periods in their history. Broad stock market indices the S\&P 500, the Nasdaq 100, and the Russell 2000 collapsed and rebounded with extraordinary velocity. The aimed efficient market dissolved in few minutes by means of high performances automated software and combination of human and algorithmic trading. Starting from the experience of the flash crashes, solutions have been proposed to improve market efficiency varying from a tax on all financial transactions to imposing delays on the cancellation or modification of resting orders or restricting directional changes in prices on a security-by-security basis, e.g., see Easley et al. (2011). In order to limit the flash crashes it is suggested either to introduce economic frictions or to have a technological involution by decelerating hardware, software and telecommunication, another punch to modern economic theory, to idealized free-market economy, to the rational expectations and to their inability to admit the possibility of endogenous a crisis.

Finally, it is worth remarking that beside productivity improvements, social changes, unexpected inefficiencies, etc. determined by information technologies, computers have also affected tremendously the development of science.

Appel et al. (1997) proved mathematically that every planar map is four colorable. The demonstration is the first in the world achieved by a computer: it took more than $1200 \mathrm{~h}$ on three different computers, but it was the first time that a mathematical theorem was proved by a computer.

Appel, Haken and Koch were the pioneers, but many followed and nowadays developments of science largely resort to computers. In Schelling's (1969) work on segregation one can find a milestone in the study of social systems and the foundations for the application of agent-based modeling to social, economic and financial systems. Agentbased modelling took direct advantages from the advances in information technologies and become a scientific method for social sciences in general and for economics and 
finance in particular. The seminal works by Kirman $(1989,1992,1993)$ have opened a new vista on economics, leading first to agent-based computational economics and finance in the 90's and then to agent-based macroeconomics in the early 2000. The UE FP6-FET project EURACE 2006-2010 (www.eurace.org), coordinated by the team at the University of Genova launched agent-based macroeconomics (Cincotti et al., 2012; Holcombe et al., 2013) and since then the research field significantly grown worldwide in general (Dawid \& Delli Gatti, 2018) and in Italy in particular (Dosi \& Roventini, 2017; Gallegati et al., 2017).

The economy is the archetypal of a complex system, as stated by Herbert Simon (1962): "[r]oughly, by a complex system I mean one made up of a large number of parts that interact in a nonsimple way. In such systems, the whole is more than the sum of the parts, not in an ultimate, metaphysical sense, but in the important pragmatic sense that, given the properties of the parts and the laws of their interaction, it is not a trivial matter to infer the properties of the whole. In the face of complexity, an inprinciple reductionist may be at the same time a pragmatic holistic". Simon published his work ten year before "More is different" by Anderson (1972) and posed the foundations of agent-based macroeconomics where the economy is represented as a nonlinear dynamic stochastic heterogeneous reflexive system.

In the framework of complexity, the scientific question moves from neoclassical problems on uniqueness and stability of the equilibrium in the economic systems to the theoretical determination of the conditions for self-referential situations characterized by the self-fulfilling prophecy of the economy. Simultaneously, the economic agents move from perfectly rational agents able to forecast the future without systematic errors to badly-informed bounded-rational ones that create their future.

It is worth remarking that aiming at facing the complexity of the economy further supports the need of a new alliance between economics and engineering, as well as with other disciplines, and the corresponding scientific questions lead to fundamental problems, potentially the continuation of David Hilbert's problems in XXI century.

\section{Final remarks}

Forging a new alliance between economics and engineering by Sergio Mariotti offers an accessible introduction to understanding the evolution of the relationships between economics and engineering and present the opportunity for a new cooperation aiming at facing both fundamental and practical problems. The questions arising from the complexity of the economic system are relevant with tremendous impacts on billions of people and there is the need of a meeting between peers, respecting the disciplinary singularities and the different cultures, but in a context of cross-fertilization, interdisciplinarity and transdisciplinarity to face them.

Funding Open access funding provided by Università degli Studi di Genova within the CRUI-CARE Agreement.

Open Access This article is licensed under a Creative Commons Attribution 4.0 International License, which permits use, sharing, adaptation, distribution and reproduction in any medium or format, as long as 
you give appropriate credit to the original author(s) and the source, provide a link to the Creative Commons licence, and indicate if changes were made. The images or other third party material in this article are included in the article's Creative Commons licence, unless indicated otherwise in a credit line to the material. If material is not included in the article's Creative Commons licence and your intended use is not permitted by statutory regulation or exceeds the permitted use, you will need to obtain permission directly from the copyright holder. To view a copy of this licence, visit http://creativecommons.org/licen ses/by/4.0/.

\section{References}

Anderson, P. W. (1972). More is different. Science, 177(4047), 393-396. https://doi.org/10.1126/science.177. 4047.393

Appel, K., Haken, W., \& Koch, J. (1997). Every planar map is four colorable. Illinois Journal of Mathematics, 21(3), 439-567. https://doi.org/10.1215/ijm/1256049012.full

Black, F. (1971). Toward a fully automated exchange. Part I. Financial Analysts Journal, 27(4), 29-34. https://doi.org/10.2469/faj.v27.n4.28

Blockley, D. I. (2020). Economics and engineering: A foreword. History of Political Economy, 52(S1), 1-9. https://doi.org/10.1215/00182702-8717886

CFTCS-SEC. (2010). Findings regarding the market events of May 6, 2010. Report of the Staffs of the CFTC and SEC to the Joint Advisory Committee on Emerging Regulatory Issues. https://www.sec.gov/news/ studies/2010/marketevents-report.pdf. Accessed 6 Oct 2021

Cincotti, S., Raberto, M., \& Teglio, A. (2012). The EURACE macroeconomic model and simulator. In M. Aoki, K. Binmore, S. Deakin, \& H. Gintis (Eds.), Complexity and institutions: Markets, norms and corporations (pp. 81-106). Palgrave Macmillan.

Dawid, H., \& Delli Gatti, D. (2018). Agent-based macroeconomics. In D. Hommes \& D. LeBaron (Eds.), Handbook of computational economics (Vol. 4, pp. 63-156). Elsevier B.V.

Dosi, G., \& Roventini, A. (2017). Agent-based macroeconomics and classical political economy: Some Italian roots. Italian Economic Journal, 3(3), 261-283. https://doi.org/10.1007/s40797-017-0065-Z

Duarte, P.G., \& Giraud, Y. (Eds.) (2020). Economics and engineering: Institutions, practices, and cultures. History of Political Economy, 52(S1), 1-332

Easley, D., López de Prado, M., \& O'Hara, M. (2011). The microstructure of the 'flash crash': Flow toxicity, liquidity crashes and the probability of informed trading. The Journal of Portfolio Management, 37(2), 118-128. https://doi.org/10.3905/jpm.2011.37.2.118

Freeman, C. (2009). Schumpeter's business cycles and techno-economic paradigms. In W. Drechsler, R. Kattel, \& E. S. Reinert (Eds.), Techno-economic paradigms: Essays in honour of Carlota Perez (pp. 125-144). Anthem Press.

Gallegati, M., Palestrini, A., \& Russo, A. (2017). An Introduction to agent-based computational macroeconomics. In M. Gallegati, A. Palestrini, \& A. Russo (Eds.), Introduction to agent-based economics (pp. 3-11). Academic Press.

Hayford, J. F. (1917). The relation of engineering to economics. Journal of Political Economy, 25(1), 59-63. https://doi.org/10.1086/252928

Holcombe, M., Coakley, S., Kiran, M., Chin, S., Greenough, C., Worth, D., Cincotti, S., Raberto, M., Teglio, A., Deissenberg, C., van der Hoog, S., Dawid, H., Gemkow, S., Harting, P., \& Neugart, M. (2013). Large-scale modeling of economic systems. Complex Systems, 22(2), 175-191. https://doi.org/10. 25088/ComplexSystems.22.2.175

Keynes, J. M. (1936). The general theory of employment, interest and money. Macmillan.

Kirman, A. (1989). The intrinsic limits of modern economic theory: The emperor has no clothes. The Economic Journal, 99(395), 126-139. https://doi.org/10.2307/2234075

Kirman, A. (1992). Whom or what does the representative individual represent? Journal of Economic Perspectives, 6(2), 117-136. https://doi.org/10.1257/jep.6.2.117

Kirman, A. (1993). Ants, rationality and recruitment. Quarterly Journal of Economics, 108(1), 137-156. https://doi.org/10.2307/2118498

Lucas, R. (1976). Econometric policy evaluation: A critique. In K. Brunner \& A. Meltzer (Eds.), The Phillips curve and labor markets (pp. 19-46). North Holland.

Mariotti, S. (2021). Forging a new alliance between economics and engineering. Journal of Industrial and Business Economics. https://doi.org/10.1007/s40812-021-00187-w

Morgan, M. S. (2012). The world in the model: How economists work and think. Cambridge University Press. 
Phillips, A. W. (1958). The relation between unemployment and the rate of change of money wage rates in the United Kingdom, 1861-1957. Economica, 25(100), 283-299. https://doi.org/10.1111/j.1468-0335. 1958.tb00003.x

Schelling, T. C. (1969). Models of segregation. American Economic Review, 59(2), 488-493. https://www. jstor.org/stable/1823701. Accessed 6 Oct 2021

Schumpeter, J. A. (1943). Capitalism, socialism and democracy. George Allen and Unwin.

Schwab, K. (2016). The fourth industrial revolution: what it means, how to respond. World Economic Forum.

Simon, H. A. (1962). The architecture of complexity. Proceedings of the American Philosophical Society, 106(6), 467-482.

Trichet, J.C. (2018). Reflections on the nature of monetary policy non-standard measures and finance theory. Opening Speechat ECB Central Banking Conference Frankfurt. https://www.ecb.europa.eu/ press/key/date/2010/html/sp101118.en.html. Accessed 6 Oct 2021

Publisher's Note Springer Nature remains neutral with regard to jurisdictional claims in published maps and institutional affiliations. 